\title{
A ótica dos usuários sobre a oferta do atendimento fonoaudiológico no Sistema Único de Saúde (SUS) em Salvador
}

\author{
The users' view on the delivery of speech therapy \\ in the Brazilian Unified Health System in Salvador (Bahia, Brazil)
}

Leda $\mathrm{M}$ aria Fonseca Bazzo ${ }^{1}$

Ceci Vilar Noronha²

\footnotetext{
${ }^{1}$ Departamento de

Fonoaudiologia,

UniversidadeFederal da

Bahia. Rua Reitor Miguel

Calmon $s / n$, Vale do

Canela. 40110-903

Salvador BA.

bazzoleda@hotmail.com

${ }^{2}$ Instituto deSaúde

Coletiva, Universidade

Federal da Bahia.
}

Abstract This article intends to analyze the supply of speech therapy services by the Brazilian Unified $\mathrm{H}$ ealth System in the city of Salvador. We have made thirty interviews with users at eight healthcare facilities, in differentiated shifts and we verified that the offer of speech therapy, in this city, is directed to medium and high complexity patients. There is a random and unequal distribution of services at sanitary districts. We have also noticed the multiple difficulties faced by users in accessing this treatment, which can be explained by the specialization of the offer, the network fragmentation and the deficit in speech therapy procedures, estimated in 131,315 per year. Therefore, regarding the concept of fair or bearable inequalities, and in order to reverse the inequities in the access to speech therapy, we suggest an urgent planning for this treatment in the three levels of attention.

Key words Speech therapy attention, Supply, Access, User's satisfaction, Brazilian Unified Health System
Resumo Este artigo tem por objetivo analisar a oferta do atendimento fonoaudiológico do SUS no município de Salvador. Realizamos trinta entrevistas com usuários, em oito serviços de saúde e em turnos diferenciados, e constatamos que a oferta do atendimento de fonoaudiologia, neste município, encontra-se direcionada para pacientes da média e alta-complexidade. Há uma distribuição aleatória e desigual dos atendimentos nos distritos sanitários. Constatamos as múlti plas dificuldades dos usuários no acesso a este cuidado, que podem ser explicadas pela especialização da oferta, pela fragmentação da rede e déficit dos procedimentos fonoaudiológicos, estimado em 131.315 por ano. Em di reção à aproximação do conceito de desigual dades justas ou suportáveis e para reverter às iniquidades do acesso à fonoaudiologia, sugerimos a urgência do planejamento deste cuidado nos três níveis de atenção. Palavras-chave Atenção fonoaudiológica, O ferta, Acesso, Satisfação dos usuários, SUS 


\section{Introdução}

A discussão relativa à oferta de serviços de saúde expressa o debate sobre os princípios que subjazem a capacidade dos gestores em manejar as políticas públicas de saúde consoante com o SUS. Por conseguinte, este artigo tem por objetivo analisar a oferta do atendimento fonoaudiólogico pelo Sistema Único de Saúde (SUS) no município de Salvador, a partir de duas dimensões: a caracterização dos serviços em relação ao quantitativo e distribuição geográfica, eaquela relativa ao acesso das pessoas, pois prevalece a idéia de que 0 acesso é uma dimensão do desempenho dos serviços de saúde associado à oferta ${ }^{1}$. Para a análise do acesso, privilegiamos as narrativas dos usuários, sujeitos demandantes do cuidado fonoaudiológico, que estavam em atendimento.

A observação relativa ao ingresso do usuário ao tratamento fonoaudiológico levou em consideração o conceito de acesso e o de acessibilidade. $\mathrm{Ou}$ seja, consideramos para a investigação do acesso 0 momento de identificação do problema fonoaudiológico ea busca por solucioná-lo²; já a acessibilidade relaciona-se com os possíveis obstáculos geográficos envolvidos ${ }^{3}$. Todavia, a literatura sobre 0 acesso arrola inúmeros fatores que podem influenciar as barreiras do acesso e utilização dos serviços de saúde. Essas podem ser resumidas em quatro grandes categorias: aspectos demográficos; aspectos de indicadores de saúde em geral; aspectos comportamentais e culturais e a organização e planejamento das ações de saúde4.

A motivação para realizar este estudo teve origem na escuta de moradores de um bairro perifé rico de Salvador, cujas queixas relativas à dificuldade de acesso aos serviços de fonoaudiologia pelo SUS eram frequentes. A partir disso, nos indagamos: como se realiza a entrada dos usuários no atendimento fonoaudiológico pelo SUS? Quais os cuidados fonoaudiológicos público oferecidos à população de Salvador?

Estudiosos que analisam a oferta de serviços de saúde indicam o aumento da demanda e consumo de serviços de saúde relacionados ao crescimento da oferta que os induz $z^{5-8}$. Se entendermos esta premissa como verdadeira, é lícito admitirmos também a existência de demandas e necessidades reprimi das pela insuficiente oferta de açõese de serviços públicos de saúde.

O tema apresenta-se, portanto, multifacetado, eno intento deminimizar estes vieses, partiu-se de duas estratégias: documentar o curso dos usuários em direção ao atendimento fonoaudiológico, tendo como referências pesquisadores que anali- sam 0 assunto pela ótica das desigualdades do acesso ${ }^{6,8-13}$, e mensurar um quantitativo da necessidade deste atendimento a partir do planejamento paramétrico.

Podemos dizer que existe relativo consenso formulado pelos especialistas de que a oferta de serviços de saúde deveria ser conformada com relação às demandas e às necessidades da população. As demandas em saúde são expressas na atitude do indivíduo em procurar serviços de saúde e se beneficiar do atendimento quando consciente de seu diagnóstico ${ }^{14,15}$. Já as características das necessidades em saúde são de difícil identificação. Por parte dos usuários, há dificuldades do reconhecimento deum problema desaúde, pelo desconhecimento das pessoas daquilo de que precisam, pela desinformação sobre a existência da solução de seus problemas, e pela insuficiência ou ausência de oferta dos serviços desejados ${ }^{16}$. Já da parte dos profissionais, a literatura adverte a identificação de necessidades de saúde no grupo populacional relacionada à lógica expansionista do mercado, ou seja, o uso nem sempre referido às exigências do próprio usuário ${ }^{5}$.

Daí a importância do estabelecimento de parâmetros sem perder de vista o debate em torno do tema. Alguns autores apontam a conformidade da oferta de serviços à análise da situação de saúde pelos estudos epidemiológicos, pelas demandas e pelas noções de necessidades como os apresentados nos estudos ${ }^{17-20}$. Assim, as pesquisas enfatizam a importância dos profissionais de saúdeidentificarem as necessidades ampliadas dos indivíduos, o que pode ser feito durante 0 acolhimento aos usuários em unidades de saúde, e com isso alcançar a integralidade da atenção.

Já a literatura da oferta explora a teoria do iceberg, em quea parte submersa indicaria a magnitude dos indivíduos em estado de necessidade, mas que não chegam a receber serviços, constituindo neste caso as necessidades latentes. A parte emersa representaria a parte da população que efetivamente busca assistência, necessidade manifesta ou demanda ${ }^{21}$.

Contudo, a necessidade de fonoaudiólogos no SUS podeser indicada pelo reconhecimento de uma população-alvo, circunscrita às estimativas de populações portadoras de deficiências e de doenças graves que ocasionam distúrbios de comunicação. Destemodo, o fonoaudiólogo énecessário ao atendimento de pacientes que apresentam sequelas provenientes das doenças cérebro-vasculares, doenças isquêmicas do coração, neoplasias de cabeça e pescoço, traumatismos crânios encefálicos, queimaduras e corrosões de cabeça e pescoço, afecções perinatais e anomalias congênitas. Também se faz necessário 0 atendimento fonoaudiológico nos 
casos de psicoses e de retardo do crescimento e desenvolvimento ${ }^{22}$

Corroborando para chegarmos a uma estimativa da necessidade defonoaudiólogos, o $\mathrm{M} \mathrm{i-}$ nistério da ustiça utilizou o censo de 2000 realizado pelo IBGE everificou que 24,5 milhões de pessoas ou $14,5 \%$ da população brasileira são portadores de alguma deficiência nas seguintes porcentagens: $48,1 \%$ delas têm deficiência visual, $41 \%$, deficiênciasfísicas; $8,3 \%$, deficiências mentais; $22,9 \%$, deficiências motoras e 16,7\%, deficiência auditiva ${ }^{23}$. As ações do fonoaudiólogo relacionam-se às deficiências auditivas, deficiências motoras e físicas, pois, em média, 50\% destas duas deficiências são acompanhadas de problemas de fala, exigindo a intervenção deste profissional ${ }^{21}$. $\mathrm{N}$ as deficiências mentais, as ações do fonoaudiólogo auxiliam o processo deaprendizagem: do desenvolvimento da linguagem oral, da motricidade para a fala e da leitura eescrita.

Observamos também que a prevalência das neoplasias de cabeça e pescoço são da ordem de $1,7 \%$ na população brasileira ${ }^{24}$, necessitando-se, nestes casos, do fonoaudiólogo desde o momento do diagnóstico às intervenções realizadas na fase pós-cirúrgica.

Ademais, a Lei $n^{\circ} 696 / 1981$, que regulamenta 0 exercício da profissão do fonoaudiólogo e esclarece suas competências, declara: Parágrafo único. Fonoaudiólogo é o profissional, com graduação plena em Fonoaudiologia, que atua em pesquisa, prevenção, avaliação e terapia fonoaudiológica na área da comunicação oral e escrita, voz e audição, bem como em aperfeiçoamento dos padrões da fala e da $v_{0 z^{25}}$. Já a lei de diretrizes e bases para a graduação do profissional fonoaudiólogo do ano de2002 atualiza o debate e amplia as competências e as habilidades desta profissão.

N esta última resolução, segundo o artigo 40 do primeiro parágrafo, A tenção à saúde: os profissionais de saúde, dentro de seu âmbito profissional, devem estar aptos a desenvolver ações de prevenção, promoção, proteção e reabilitação da saúde, tanto em nível individual quanto coletivo ${ }^{26}$.

Destemodo, no marco da regulamentação deste profissional, assim como a lei que regula a formação do fonoaudiólogo, estão previstas ações de prevenção, promoção, reabilitação e tratamento e, ao se tratar de serviços públicos de saúde, sublinha-se a importância da sua atuação, consoante ao modelo de atenção em saúde proposto pelo SUS.

\section{M etodologia}

Num primeiro momento, a metodologia deste estudo consistiu na coleta de dados secundários obtidos pelo site DataSUS no intento de verificar a quantidade de serviços fonoaudiológicos disponíveis pelo SUS no município de Salvador. A coleta dos dados foi realizada entre os meses de novembro de 2005 e fevereiro de 2006. 0 procedimento no site indicado foi a consulta ao link indicadores; neste, selecionamos a classificação brasileira de ocupação (CBO) Fonoaudiólogo; estado da Bahia, município de Salvador. Posteriormente, as informações foram checadas por telefone e pela procura direta nos serviços para validação.

A segunda fase metodológica deste estudo se assenta em uma abordagem qualitativa, com a realização de trinta entrevistas com usuários que estavam em atendimento fonoaudiólogico pelo SUS, em oito dos quatorze serviços que oferecem esta terapia no município. Este projeto de pesquisa foi submetido e aprovado pelo Comitê de Ética em Pesquisa do Instituto deSaúde Coletiva da Universidade Federal da Bahia.

As entrevistas com os usuários foram conduzidas com um roteiro que funcionou como um documento orientador, constando questões relativas a meios de acesso do usuário ao serviço de fonoaudiologia; distância entre a residência e 0 serviço; número de estabelecimentos procurados; tempo transcorrido da identificação do problema até o início da terapia fonoaudiológica; satisfação do usuário com a terapêutica e sugestões de meIhoria do atendimento.

Privilegiamos para as entrevistas um primeiro contato interativo com os usuários, possíveis sujeitos do estudo, explicamos os propósitos do trabalho, o sigilo das informações e identidade dos entrevistados, além das eventuais contribuições do estudo em direção a uma possível reorganização da rede de serviços fonoaudiológicos do SUS em Salvador. 0 diálogo ocorreu em uma sala disponibilizada pelo serviço; porém, na ausência desta possibilidade, uma pequena parte das entrevistas foi efetuada no espaço de sala de espera.

A realização destes encontros nos serviçosocorreu entre os meses de abril e julho de 2006. Foi realizada também a observação direta nas instituições com anotações pessoais em diário de campo, que serviram para compor a análise dos resultados. Todas as entrevistas foram gravadas em fita 
cassete e transcritas para a análise. Para o tratamento do material empírico, foi utilizada a análise de conteúdo.

Conforme sugerido pela análise de conteúdo, fizemos uma decomposição das entrevistas a partir de unidades selecionadas que se repetiam entre os entrevistados e do que era peculiar a cada um deles ${ }^{27}$.

Paralelamente, utilizamos a Portaria no 1.101/ 2002 em consonância com o plano municipal de Saúde de Salvador para estabelecer um parâmetro à organização da oferta dos serviços de saúde neste municípi ${ }^{28,29}$. Entretanto, dada a ausência de parâmetros específicos para os procedimentos em fonoaudiologia, o recurso foi utilizar o critério "outros profissionais de saúde de nível superior", estipulado em 0,11/procedimentos/ habitante/ano. Assim, fizemos uma estimativa dos procedimentos fonoaudiológicos efetuados nos serviços existentes em Salvador no ano de2005 e a comparação com a fórmula sugerida pela Portaria: total de ação = população $\mathrm{x}$ parâmetro de atendimento.

\section{A oferta de serviços fonoaudiológicos em Salvador}

A realização dos cálculos relativos às ações fonoaudiológicas recomendadas foi da ordem de 286.000 procedimentos, mas a estimativa do total de procedimentosfonoaudiológicosem Salvador em 2005 foi de 154.685 procedimentos/habitante/ano. Estes valores foram cal culados nos dezesseis serviços queno corrente ano ofereciam al gum procedimento em fonoaudiologia.

Para Salvador, acreditamos que esta recomendação de 0,11/100.000 habitantes, ainda que possa re presentar certa defasagem da oferta ou mesmo possa diferir do cálculo aplicado em outros estados, é mais realista, neste momento, para o início da organização e/ou reorientação deste cuidado em saúde.

A partir do déficit estimado em 131.315 procedimentos fonoaudiológicos por ano, verificamos a necessidade de contratação de 33 fonoaudiólogos trabalhando trinta horas/semanais para cobrir o déficit.

No entanto, ao sabermos da implementação da Política Nacional de Saúde Auditiva/2004 neste município, e do aumento destes procedimentos, advertimos atenção especial para que a expansão da fonoaudiologia não se resuma aos exames auditivos e terapêuticas exclusivas para usuários com surdez.

Encontramos em Salvador um total de cinquenta e dois fonoaudiólogos até 0 ano de 2005 que realizam procedimentos pelo SUS, seja de terapia, seja de exames auditivos. A carga horária de trabalho destes profissionais é variada, mas o total de horas ocupadas com SU S entre todos eles foi estimado em 48.928 horas/ano. As formas de contratação do fonoaudiólogo nos serviços são diversas e seguem os seguintes moldes: quatorze foram contratados pelo Regime Especial de Direito Administrativo (REDA); vinte e quatro são profissionais cooperados ou prestadores de serviços e quatorze foram contratados sob o regime da Consolidação das Leis Trabalhistas (CLT).

Ainda fundamentada na Portaria $\mathrm{n}^{\circ} 1.101 / 2002$, que prevê $63 \%$ para consultas básicas; 22\% para consultas especializadas; $12 \%$ para consultas de urgência e 3\% para consultas pré-hospitalares, assinalamos a ausência da fonoaudiologia na atenção básica. Consequentemente, este nível de atenção deveria ser o privilegiado na expansão.

Acesso aos serviços defonoaudiologia: uma batal ha a ser vencida no cotidiano

A manifestação dos usuários relativa à dificuldade quanto ao acesso geográfico foi comum nas entrevistas mas, em virtude da necessidadee da ausência de outro serviço mais próximo, permanecem no tratamento. Conforme os trechos: É dose, é muito difícil, [transporte] eu sempre reclamo, mas eu nunca consegui outro horário, porque eu tenho que che gar aqui uma hora, moro perto do aeroporto tenho que pegar dois transportes. $\mathrm{N}$ ão teve outro horário que eu conseguisse, "peguei o boi" pra conseguir [atendimento fonoaudiológico]. (U suário 16)

0 meu problema éesse, [transporte] às vezes até eu falto [à terapia fonoaudiológica], porque eu moro muito longe, eu tenho que pegar quatro ônibus pra vir aqui, ou até mais. (Usuária 11)

Acompanhamos o agravamento da dificuldade no acesso dos usuários a este tratamento pela segmentação da clientela ou a especialização da oferta do cuidado fonoaudiológico, aspecto já pesquisado ${ }^{6}$. Em observação direta nos serviços, evidenciamos a escolha destas instituições para atender determinadas patologias e constatamos a percepção desta sel eção, também, por parte dos usuários. 0 que é percebido e explicado por parte dos usuários nas seguintes expressões: Agora eu creio, não sei direito, que a E. [serviço de nome fictício], ela émais para síndrome, acho queémais síndrome, então geralmente, paralisia e outras coisas assim eu acho que não são muito dedicadas, acho que lá a dedicação é para síndrome. (U suária 13) 
$\mathrm{Na}$ época mesmo eu fui no $\mathrm{B}$. [serviço de nome fictício], aí disseque não tinha ainda, a especialidade para ele; aqui, também, eu já tinha vindo aí fiquei na fila de espera aqui. (Usuário 1)

Pudemos constatar pelas entrevistas realizadas que apenas um usuário avaliado com distúrbio articulatório mas ausente de diagnóstico de doença foi absorvido pelo serviço. Deste fato, decorre insatisfação das mães com a prolongada espera para ser admitido por algum serviço de atenção fonoaudiológica, como indica o trecho da seguinte entrevista:

No momento, a dificuldade neste serviço é que meu outro filho el eestá precisando de fono enão tem como encaixar, ou eu pago, ou eu espero pelo SU S ea fila pelo SUS tá lá embaixo. Ele passou pela triagem e está na fila, o problema dele maior é que ele pega na voz, elechupa a língua, ele está na fila deespera para fono há mais ou menos doisanos. Porqueo problema dele não dá direito a fonoaudiólogo, só para quem tem problemas mais sérios. (Usuário 24)

Outro obstáculo encontrado ao acesso dos usuários ao atendimento fonoaudiológico pelos SUS deve-se ao desconhecimento dos profissionais de saúde quanto aos locais onde são oferecidas as terapias. Em geral, os usuários recorrem à sua própria rede de conhecimentos para contornar as dificuldades de acesso, conforme os seguintes fragmentos das entrevistas: A médica não indicou este serviço, a gente saiu procurando e chegamos aqui e encontramos. Não consegui nada, de jeito nenhum. Falou que não tinha vaga [ $p a r a$ atendimento fonoaudiológico] e estava um pouco difícil. (U suário 15)

$\mathrm{N}$ ós procuramos através de pessoas que a gente conhece, como médico. E eles não sabiam informar. $O$ Y [instituição de nome fictício] não tem [atendimento fonoaudiológico], o X [ serviço de nome fictício] não faz [atendimento fonoaudiológico], então é recente. (U suário 6)

Pudemos observar nas entrevistas a dificuldadedeencontrar a terapia fonoaudiológica pelo SUS, ao deparar-se com o serviço que oferece este atendimento, existe ainda a dificuldade pela especialização da oferta. 0 diálogo com os usuários mostrou sua procura em dois, três ou quatro serviços sem sucesso, até chegar ao serviço utilizado no momento da entrevista. A seguir trechos das entrevistas esclarecedores: Sabia que meu filho precisava de fono, só nunca consegui. Sempre me deixavam na fila de espera, eu nunca consegui. $\mathrm{Na}$ época mesmo, eu fui no $Y$ [instituição], aí disse que não tinha ainda, a especialidade para ele; aqui, também, eu já tinha vindo ai fiquei na fila de espera aqui. (U suário 1)

Procurei o hospital e depois teve outro, mas só que eu não sei o nome da clínica; e ela encaminhou para outro hospital, no outro centro de atendimento, só que lá a fono só atendia adolescente e adulto. (U suário 14, quarto serviço procurado)

Em virtude destes obstáculos, investigamos que 0 atraso para iniciar o tratamento pode variar entre um a dez anos (exceto nos casos de AVC, AVE entre adultos e paralisia cerebral infantil, quando encaminhados para os locais corretos de referência destas doenças) após sentirem a necessidade deste cuidado, como indicado em dezessete entre vistas com os usuários (Anexo 1).

A situação do acesso a este cuidado se agrava para os usuários deste município, pois existe a concorrência das vagas com a população dos municípios vizinhos carentes deste cuidado, como revelam os usuários 1, 2, 20, 25 e 26 (Anexo 1).

Observamos dificuldades entre a capacidade instalada dos serviços para cobrir a população deste município, mostrando-se ainda mais perversa a incumbência de suprir as demandas e necessidades da população das outras regiões neste tratamento.

\section{A satisfação com os serviços \\ defonoaudiologia: uma quimera?}

Entendemosqueosusuários do serviço defonoaudiologia do SUS percebem a oferta deste cuidado como insuficiente, pois foi comum eles sugerirem maior quantidade de fonoaudiólogos nos serviços de saúde, visto que, mesmo estando em atendimento, conhecem pessoas que procuram as instituições e ficam sem respostas para esta necessidade de saúde. Este aspecto é evidenciado na fala dos usuários: Eu acharia que deveria ter mais fono, porque tem muita genteque está na lista de espera enão consegue, porque acho que tem pouco, tem muita gente e pouco fono. (Usuário 8)

Aqui, precisa de mais profissional porque têm muitascriançasiguaisa elequenão estão sendo atendidas pela fono porque não conseguem vaga; como eu, tenho outras colegas também que já veio procurar, só que estão na lista de espera. Não têm vaga. Passam pela triagem, deixam o nome, assim quetem uma vaga ela te chama. Quando alguém desiste alguma coisa assim, aí chama outra criança, várias crianças estão precisando do trabalho de fono e não encontra profissionais. (Usuário 14) 
A redução da oferta do atendimento fonoaudiológico propicia a participação dos cuidadores; as mães, em geral, se especializam nos exercícios e nas atividades realizadas pelo fonoaudiólogo, que se estende também para os usuários adultos como forma de potencializar os efeitos na garantia de melhor prognóstico. A seguir, trechos queilustram esse ponto de vista: Também entro, porque senão ele não fica. Eu gosto, [deentrar na terapia de fono] tem coisas que eu aprendo também para chegar em casa e ensinar a ele. (U suário 7; demanda de atraso de linguagem, suspeita de deficiência auditiva edificuldades de mastigação)

Boto no meu caderno [os exercícios] eesses aqui pra mim é como se fosse uma religião, tenho que rezar todo dia; então eu faço isso aqui [mostra o caderno], todos estão aqui, boto no banheiro. No papelzinho perto da minha escova de dente, antes de escovar os dentes, faço três vezes por dia. (U suário 5)

Foram inúmeras as sugestões dos usuários para melhoria do atendimento fonoaudiológico; porém, ao direcionarmos a pergunta objetiva, partesignificativa deles não soube responder, ou mesmo não apresentou nenhuma proposta. A seleção do trecho destacado pode nos revelar pistas relativas ao exame deste pensamento, já que os usuários entre vistados faziam parte de um grupo seleto, ao le varmos em conta a disputa para 0 atendimento fonoaudiológico pelo SUS. A seguir o trecho da entrevista resume, em parte, a ausência de sugestões dos demais usuários: Não, [tem alguma sugestão] para mim está bom; pra mim está bom né, estou sendo atendida, o importante é isso, o dia que marca ela atende! (Usuário 29)

Não. [sugestão] Eu achei tudo muito bem. Porque me botaram. (Usuário 9)

Outra idéia subjacente à inexistência de sugestões é de que as instituições estão prestando um favor ao oferecer o serviço fonoaudiológico, pois muitos deles não relacionam o serviço apresentado com o governo, gestor e financiador da atenção aos casos estudados. Por outro lado, a interpretação é que as autoridades de saúde pouco se esforçam para aumentar a oferta. A seguir, trecho de uma entrevista reveladora desta idéia: $A$ sugestão de melhoria infelizmente não tenho, porque dependia muito do governo ter atitude, ser mais coerente, mais correto, ol har mais para as pessoas quenão têm condições, mas isso ele não faz e aí pessoas como a organização aqui abre as portas, mas não consegue atender a demanda [por fonoaudiologia], que é muito grande. 0 governo não faz nada eaí as poucas pessoas que têm [as instituições] não têm condições de abranger toda a cidade. (U suário 6)

A pesar de todos os transtornos passados, foi quase unânime a satisfação dos usuários referente à terapia de fonoaudiologia, por um lado, por terem conseguido o tratamento mesmo com as adversidades e, por outro, os resultados da terapêutica contribuem para o fato, como pode ser visto logo abaixo: Porque estou vendo o desenvolvimento dele, [com o tratamento fonoaudiológico] a progressão, porque ele está progredindo; então a gente tem mais é que agradecer. (Usuário 1)

Eu tô achando, porque ele quer falar alguma coisa e está fazendo som; pra mim ele está melhorando bastante, ele não fazia nada; está mel hor. Estou [satisfeita com 0 atendimento] porque ela é ótima médica [a fonoaudióloga], trata a criança muito bem e também ela está ensinando elea falar. Elenão sabia mastigar, tá aprendendo já. (Usuário 7)

Os usuários falaram da representação do profissional de fonoaudiologia e da abertura dos cursos de formação na área por universidades e faculdades de Salvador, fato este que poderia impulsionar a expansão da oferta deste cuidado em saúde para o Sistema Único de Saúde (SUS) ou para o setor privado. Neste sentido, tivemos um depoimento que assinala o desconhecimento das pessoas referente aos objetivos e a importância do fonoaudiólogo para a sociedade. Seguetrecho deuma entrevista: 0 atendimento de fono pra mim no que diz respeito ao atendimento pelo SUS abriu expandiu um pouco. Para a faculdade estar formando muito mais especialistas eaté essa abertura maior etodo mundo tá ganhando com isso, toda a sociedade tá ganhando, tá ganhando maisespecialistas, maisatendimento, agora preciso obter mais informação, ainda tá um pouco fechado, as pessoas não estão acostumadas, estão achando que é moda, que é invenção, que é só uma invenção a mais. Então o pessoal não está percebendo qual éo objetivo deste especialista ea necessi dade de seter esse especialista no mercado ede estar contribuindo para a permanência dele em todo o nosso convívio: nas escolas, escolas especializadas e não especializadas. (U suário 25)

Verificamos que durante os longos tratamentos fonoaudiológicos estão presentes a criatividade e a implicação dosusuários, como um modo de ajudar a resolução dos problemas apresentados. A percepção dos usuários sobre a oferta insuficiente do serviço fonoaudiológico disponibilizado pelo SUS contribui para a reconstituição da terapia em casa. Em geral, as técnicas oferecidas na sessão fonoaudiológica e executadas junto com os usuários ganham contornos alquímicos para o pacientee a sua reprodução éa "garantia" de sucesso na reabilitação.

Deste modo, as dificuldades enfrentadas, como o prolongado tempo de espera e a troca de fonoaudiólogos durante 0 tratamento, podem ser sublimadas, por parte dos usuários, se eles conseguirem obter em contrapartida exercícios devidamente 
transmitidos. E o caráter quase mítico conferido a este profissional pelos usuários em processo terapêutico contribui para divulgar uma visão ealcance geral das ações fonoaudiológicas para além das condizentes com o estágio de reabilitação.

\section{Discussão}

A distribuição da oferta do atendimento fonoaudiológico nos distritos sanitários éinsuficientee desigual, corroborando para as dificuldades apontadas pelos usuários para obter acesso a este cuidado. A insuficiência deste serviço atingeo déficit calculado em 131.315 procedimentos/ano. A oferta é desigual por verificarmos distritos sanitários com até seis serviços fonoaudiológicos pelo SUS ea inexistência do atendimento em outros seis distritos.

Estão à margem da oferta dos cuidados fonoaudiológicos os distritos sanitários de Cabula/ Beiru, Subúrbio Ferroviário, Cajazeiras, Itapuã, São Caetano e Centro Histórico, os quais deveriam, a partir da oferta regida pelo princípio da equidade, serem espaços merecedores desta atenção em saúde. A análise revela a preferência da oferta do atendimento fonoaudiológico nos espaços luminosos, ou seja, locais com grande dinamismo comercial, ou mesmo a ausência deste cuidado nos espaços opacos, territórios da cidade com pouca luminosidade, vulneráveis a problemas de infraestrutura e onde proliferam os problemas ${ }^{30}$.

Examinamos a existência de um extenso percurso do usuário de modo frustrado em várias instituições no intento de conseguir 0 atendimento fonoaudiológico. Consequentemente, o gap entre o problema sentido, a procura e a absorção destes pacientes para o tratamento ocorre com a identificação tardia do problema de saúde, o que pode comprometer os benefícios deste cuidado. Esta defasagem entre o diagnóstico e tratamento evidentemente agrava o problema de saúde; nos casos de pacientes infantis, retarda o desenvolvimento destegrupo às habilidades linguísticas e cognitivas ou mesmo nos adolescentes e adultos contribui para a perpetuação de um sofrimento evitável.

0 quadro delineado em Salvador, no que tange à oferta de fonoaudiologia, parece obedecer à lógica da el egibilidade deal guns usuários e exclusão da maioria. A naturalização das distâncias geográficas entre os serviços e o local de residência dos usuários, a desatenção ao tempo e despesas despendidas no deslocamento dos pacientes, a desinformação dos técnicos de saúde sobre outras instituições para terapia fonoaudiológica, consequente da falta de organização e comunicação da rededeste cuidado, são aspectos que afetam 0 acesso ${ }^{15}$.
Os resultados ora analisados configuram que a oferta do atendimento fonoaudiólogo em Salvador está disponível de maneira simplificada, focalizada, seletiva e responde a uma determinada demanda, em geral, tecnicamente atrasada, conforme observou Assis para a rede assistencial como um todo, na cidade de Feira de Santana (BA $)^{10}$.

Portanto, a atitude dos gestores para organizar a rede de cuidados fonoaudiológicos parte de reconhecer os prejuízos da sua fragmentação da assistência, situação que intensifica o problema ao observarmos que Salvador, mesmo com reduzida oferta do serviço fonoaudiológico, recebe usuários de outros municípios para o tratamento. Observamos, deste modo, a ausência da planificação deste cuidado como recomendados pela NOAS/ 2002 ao estabelecer os municípios pólos e os municípios sedes para determinados tratamentos ${ }^{31}$.

A pontamos como desafios para a área fonoaudiológica o desenvolvimento eaperfeiçoamento de um modelo de atenção em saúde que responda as necessidades apresentadas em consonância com os princípios do SUS. Decorre daí a importância de divulgar trabalhos erelatos de experiências de processos fonoaudiológicos implementados na atenção básica, como os publicados ${ }^{32-35}$. Sabemos que a super-especialização contamina todas as áreas da saúde, processo não peculiar à fonoaudiológi$\mathrm{ca}$, e indicamos como possibilidade de concorrer com a lógica hegemônica, conhecimentos interdisciplinares eintersetoriais no empenho de construir e influenciar outras lógicas de trabalho. Estas se ocupariam essencialmente em responder pelo desenvolvimento do indivíduo no que diz respeito à diminuição das desigualdades de acesso quanto a estecuidado em saúde epressupõem um profissional generalista.

O fonoaudiólogo lotado nos serviços de atenção básica apresenta maior abrangência de suas ações e versatilidade, habilidades estas do generalista, o que poderá impactar não só no tratamento das doenças, mas também no quadro de saúde em geral. Temos ciência, no entanto, de que a resposta ao problema apresentado será além da contratação por concurso público de fonoaudiólogos na atenção básica, a deseinvestir na rede comunicante dos serviços nos três níveis de atenção do tratamento etambém em modificações de trabal ho deste profissional nos serviços. Ressalta-se ainda quea maioria das instituições visitadas mostrou dificuldades na resolutividade deste cuidado e inadequação do atendimento fonoaudiológico, tais com a espera prolongada, com variações de uma a três horas para 0 atendimento nas instituições; 0 atendimento com gruposnumerosos de usuários, o que é incompatível com os resultados esperados; a in- 
capacidade de alguns serviços responderem de forma adequada aos usuários em curto/médio prazo.

\section{Conclusões}

A pontamos para a urgência na planificação da oferta do atendimento fonoaudiológico em Salvador no intento de superar o quadro analisado. Neste sentido, indicamos a importância do atendimento fonoaudiológico ser oferecido nos três níveis de atenção, o que contribuirá para o início do funcionamento da rede regionalizada e hierarquizada deste cuidado.

Persistindo a ausência de planejamento para o tratamento fonoaudiológico, o resultado poderá ser uma super-oferta deste atendimento a curto/ médio prazo para os serviços de média e alta complexidade, e 0 aprofundamento do déficit na atenção básica. Tais efeitos expressariam um retrocesso para a concretização da integralidade e da universalidade da atenção fonoaudiológica.

E ao identificarmos as áreas prioritárias para a implementação deste cuidado em saúde, propomos aproximar a oferta do tratamento fonoaudiológico do conceito de desigualdades justas ou suportávei $s^{36}$, ou a um conceito dejustiça "a cada um o mesmo, de acordo com suas necessidades" ${ }^{17}$. Em suma, visamos relacionar os conceitos de chances iguais ao fonoaudiólogo para os indivíduos pertencentes a classes sociais diferentes no intento de diminuir as desigualdades no acesso identificadas a este cuidado em saúde.

\section{Colaboradores}

LM F Bazzo e CV Noronha participaram igualmente de todas as estapas da elaboração do artigo.

\section{Referências}

1. Travassos C, Martins M. Uma revisão sobre os conceitos de acesso e utilização de serviços de saúde. Cad Saude Publica 2004; 20(Supl. 2):S190-S198

2. Andersen R. M. Revisiting the behavioral model and access to medical care: does it matter? J. Health Soc Behav 1995; 36:1-10.

3. Donabedian A. An introduction to quality assurance in health care. New York: Oxford University Press; 2003.

4. Moreira RS, Nico LS, Tomita NE, Ruiz T. A saúde bucal do idoso brasileiro: revisão sistemática sobre 0 quadro epidemiológico e acesso aos serviços de saúde bucal. Cad Saude Publica 2005; 21(6):1665-1675.

5. Paim JS. As ambiguidades da noção de "necessidades de saúde". In: Paim JS, Almeida Filho N. Introdução à crítica do planejamento de saúde. Salvador: U FBA; 1982.

6. Santos MAB, Gerschman S. Segmentations of health service supply in Brazil: institutional arrangements, creditors, payers and providers. Cien Saude Colet 2004; 9(3):795-806.

7. Oliveira EXG, Travassos C, Carvalho MS. Acesso à internação hospitalar nos municípios brasileiros em 2000: territórios do Sistema Ú nico de Saúde. Cad Saude Publica 2004; 20(Supl. 2):S298-S309.

8. Castro M SM , Travassos C, Carvalho M S. Efeito da oferta de serviços de saúde no uso de internações hospitalares no Brasil. Rev. Saude Publica 2005; 39(2):277-284.

9. Araújo M AL, Leitão GCM. Acesso à consulta a portadores de doenças sexualmente transmissíveis: experiências de homens em uma unidade de saúde de Fortaleza, Ceará, Brasil. Cad Saude Publica 2005; 21(2):396-403. 
10. Assis MMA, Villa TCS, Nascimento MAA. Acesso aos serviços de saúde: uma possibilidade a ser construída na prática. Cien Saude Colet 2003; 8(3):815-823.

11. Silva PLB. Serviços de Saúde: o dilema do SUS na nova década. São Paulo em Perspectiva 2003; 17(1):69-84.

12. Neri M, Soares W. Desigualdade social e saúde no Brasil. Cad Saude Publica 2002;18(Supl.):77-87.

13. Cohn A, Elias PEM. Equidade e reformas na saúde nos anos 90. Cad Saude Publica 2002; 18(Supl.):173-180.

14. Pinheiro R. As práticas do cotidiano na relação oferta e demanda dos serviços de saúde: um campo de estudo e construção da integralidade. In: Pinheiro R, $M$ attos RA, organizadores. Os sentidos da integralidade na atenção e no cuidado à saúde. Rio de Janeiro: IMS/UERJ; 2001. p. 65-112.

15. Travassos C, Oliveira EXG, Viacava F. Desigualdades geográficas e sociais no acesso aos serviços de saúde no Brasil: 1998 e 2003. Cien Saude Colet 2006; 11(4): 975986.

16. Arruda D. Sistemas de informação e alocação de recursos [dissertação]. Rio de Janeiro (RJ): Instituto de M edicina Social, UERJ; 1998.

17. Heller A. Além da justiça. Rio de Janeiro: Civilização Brasileira; 1998.

18. Heller A, Fehér F. A condição política pós-moderna. Rio de Janeiro: Civilização Brasileira; 2002.

19. Cecilio LCO. As necessidades de saúde como conceito estruturante na luta pela integralidade e equidade em saúde. In: Pinheiro R, M attos RA, organizadores. Os sentidos da integralidade. Rio de Janeiro: IM S/UERJ/ ABRASCO; 2001. p. 113-126.

20. Stotz EN. N ecessidades de saúde: mediações de um conceito (contribuição das ciências sociais para a fundamentação teórico-metodológica de conceitos operacionais da área de planejamento em saúde) [tese]. Rio de Janeiro (RJ): Escola Nacional de Saúde Pública, Fundação Oswaldo Cruz; 1991.

21. Castiel LD. 0 técnico e as necessidades em saúde. Cad Saude Publica 1985; 1(1):18-24.

22. Lessa FJD, M iranda GM D. Fonoaudiologia e Saúde Pública. In: Britto ATB, organizador. Livro de fonoaudiologia. São José dos Campos: Pulso Editorial; 2005. p. 375-386.

23. Brasil. M inistério da Justiça. Secretaria Especial dos Direitos Humanos. Censo 2000. O Brasil quer saber quantos são os portadores de deficiência. [site na Internet]. [acessado 2003 out 27]. Disponível em: http:// www.mj.gov.br/sedh/dpdh/noticias/not5.htm

24. Saúde N ews Journal. Inca investe no tratamento do câncer de cabeça e pescoço. [site na Internet]. [acessado 2007 abr 30]. Disponível em: http://209.85.165.104/ search?q=cache:YG5iIU_I2k4J: www.odontologia. com.br/noticias.asp \% 3Fid\%3D 517\%26ler\%3D s+ preval\%C3\%AAnciatdastneoplasias+de+cabe $\%$ C3\%A7a+e+ pesc 0\%C3\%A 70+na+popula\%C3\%A 7\%C3\%A30+ brasileira $\& \mathrm{hl}=\mathrm{pt}-\mathrm{BR} \& \mathrm{ct}=\mathrm{clnk} \& \mathrm{~cd}=2 \& \mathrm{gl}=\mathrm{br}$
25. Brasil. Lei $n^{\circ}$ 6.965, de 9 de dezembro de 1981. Dispõe sobre a regulamentação da profissão de fonoaudiólogo, e determina outras providências. Diário Oficial da União 1981; $10 \mathrm{dez}$.

26. Brasil. CNE. Câmara de Educação Superior 5 (CES). Institui Diretrizes Curriculares Nacionais do Curso de Graduação em Fonoaudiologia. Diário Oficial da União 2002; 4 mar.

27. Bardin L. Análise de conteúdo. Lisboa: Edições 70; 1977.

28. Brasil. Portaria no 1.101, de 12 jun. 2002. Estabelece os parâmetros de cobertura assistencial. Diário Oficial da União 2002; 13 jun.

29. Brasil. Secretaria Municipal de Saúde. Plano M unicipal de Saúde de Salvador (2006-2009). Salvador: Secretaria M unicipal de Saúde; 2006.

30. Santos M, Silveira M L. O Brasil: território de sociedade no início do século XXI. Rio de Janeiro: Record; 2001.

31. Brasil. Ministério da Saúde. Regionalização da Assistência à Saúde: aprofundando a descentralização com equidade no acesso. Norma Operacional da Assistência à Saúde - NOAS-SU S 01/01. Brasília: Ministério da Saúde; 2001.

32. Lopes EM B. Cultura, linguagem e fonoaudiologia: uma escuta do discurso familiar no contexto da saúde pública [dissertação]. São Paulo (SP): Universidade de São Paulo; 2001.

33. Mendes VLF. Uma clínica no coletivo: experimentações no programa de saúde da família [tese]. São Paulo (SP): Pontifícia Universidade Católica de São Paulo; 2004.

34. Pan C, Garcia R. Práticas populares em relação à linguagem de crianças do bairro carvalho do município de Itajaí [monografia]. Itajaí (SC): Centro de Ciências da Saúde, Universidade do Vale do Itajaí; 2004.

35. Costa PG. Oficina de Linguagem na Saúde Coletiva: uma experiência de atuação fonoaudiológica [dissertação]. São Paulo (SP): Pontifícia Universidade Católica de São Paulo; 2006.

36. Dubet F. As desigualdades multiplicadas. Rio Grande do Sul: Unijuí; 2003.

Artigo apresentado em 02/07/2007

Aprovado em 08/10/2007

Versão final apresentada em 15/10/2007 
Anexo 1. U suários do SUS nos serviços de fonoaudiologia.

\begin{tabular}{|c|c|c|c|c|c|}
\hline U suário e instituição & Idade & Sexo & $\begin{array}{c}\text { I dade de detecção } \\
\text { do problema }\end{array}$ & Diagnóstico & $\begin{array}{l}\text { Tempo de espera } \\
\text { para o atendimento }\end{array}$ \\
\hline Usuário 1/ Instituição 1 & 7 anos & M & Com 4 anos & Paralisia cerebral & 6 anos \\
\hline Usuário 2/Instituição 2 & 70 anos & M & Com 69 anos & AVC & Um mês \\
\hline Usuário 3/Instituição 2 & 46 anos & M & Com 43 anos & AVC & Um mês \\
\hline Usuário 4/Instituição 3 & 10 anos & M & Com 6 anos & Distúrbio articulatório & 4 anos \\
\hline Usuário 5/Instituição 3 & 54 anos & M & Com 54 anos & Nódulo de prega vocal & Um mês \\
\hline Usuário 6/Instituição 2 & 73 anos & M & Com 72 anos & AVC & Trêsmeses após o problema \\
\hline U suário 7/Instituição 2 & 12 anos & M & Com 9 meses & Paralisia cerebral & $\begin{array}{l}\text { Sete meses no primeiro serviço e } \\
\text { mais sete para o segundo serviço. }\end{array}$ \\
\hline U suário 8/Instituição 4 & 10 anos & M & Com 8 anos & Nódulo de prega vocal & 2 anos \\
\hline Usuário 9/Instituição 5 & 13 anos & M & Ao nascer & Paralisia Cerebral & 10 anos \\
\hline Usuário 10/Instituição 2 & 57 anos & $M$ & Com 55 anos & Aneurisma & Dois meses \\
\hline Usuário 11/Instituição 5 & 45 anos & $\mathrm{F}$ & Com 38 anos & $\begin{array}{l}\text { Nódulo de prega vocal } \\
\text { com fenda e hemorragia }\end{array}$ & 7 anos \\
\hline U suário 12/Instituição 4 & 38 anos & $\mathrm{F}$ & Com 28 anos & $\begin{array}{l}\text { Nódulo de prega vocal } \\
\text { associado a fenda }\end{array}$ & 10 anos \\
\hline U suário 13/ Instituição 2 & 12 anos & $\mathrm{F}$ & Com 9 meses & Paralisia cerebral & $\begin{array}{l}4 \text { anos e três meses no } 1^{0} \text { serviço; } \\
2 \text { anos no } 2^{-0} \text { serviço }\end{array}$ \\
\hline Usuário 14/ Instituição 7 & 4 anos & $\mathrm{F}$ & Ao nascer & Síndrome de Down & 4 anos \\
\hline U suário 15/ Instituição 4 & $\begin{array}{l}3 \text { anos e } \\
\text { seis } \\
\text { meses }\end{array}$ & M & Ao nascer & Síndrome de Down & 2 anos e seis meses \\
\hline Usuário 16/ Instituição 5 & 6 anos & M & Ao nascer & Síndrome desconhecida & $\begin{array}{l}3 \text { anos começou a procurar fono } \\
\text { e consegui logo. }\end{array}$ \\
\hline U suário 17/ Instituição 2 & 63 anos & M & Por volta de 59 & Surdez central & 3 anos depois sentir o problema \\
\hline U suário 18/ Instituição 5 & 12 anos & M & Com 7 anos & $\begin{array}{l}\text { Problemas de } \\
\text { aprendizado e distúrbio } \\
\text { articulatório }\end{array}$ & 2 anos após detectado o problema \\
\hline Usuário 19/ Instituição 1 & 3 anos & $\mathrm{F}$ & Ao nascer & Paralisia cerebral & Dois meses \\
\hline U suário 20/ Instituição 1 & 52 anos & M & Com 52 anos & AVC & 3 meses \\
\hline U suário 21/ Instituição 1 & 61 anos & M & Com 60 anos & Aneurisma cerebral & 2 meses \\
\hline U suário 22/ Instituição 5 & 38 anos & $\mathrm{F}$ & Com 37 anos & $\begin{array}{l}\text { Nódulos de pregas } \\
\text { vocais }\end{array}$ & 3 meses \\
\hline U suário 23/ Instituição 5 & 76 anos & M & Com 73 anos & AVC & 3 meses \\
\hline U suário 24/ Instituição 8 & 10 anos & M & $\begin{array}{l}\text { Com } 2 \text { anos e } \\
\text { seis meses }\end{array}$ & $\begin{array}{l}\text { Transtorno invasivo de } \\
\text { desenvolvimento }\end{array}$ & 3 anos e 6 meses \\
\hline U suário 25/ Instituição 5 & 16 anos & $\mathrm{F}$ & Ao nascer & Deficiência mental & 12 anos \\
\hline U suário 26/ Instituição 8 & 33 anos & $\mathrm{F}$ & Com 25 anos & $\begin{array}{l}\text { Fenda dupla de pregas } \\
\text { vocais }\end{array}$ & 5 anos \\
\hline U suário 27/ Instituição 1 & 26 anos & M & Com 25 anos & Traumatismo craniano & 2 meses \\
\hline U suário 28/ Instituição 2 & 55 anos & M & Com 54 anos & AVE & 1 ano \\
\hline U suário 29/ Instituição 3 & 8 anos & M & Ao nascer & Síndrome de Down & 6 anos \\
\hline Usuário 30/ Instituição 3 & 41 anos & M & Com 39 anos & Nódulo de prega vocal & 1 ano \\
\hline
\end{tabular}




\begin{tabular}{|c|c|c|c|}
\hline \multicolumn{4}{|l|}{ Anexo 1. continuação } \\
\hline $\begin{array}{l}\text { Número de } \\
\text { serviços procurados } \\
\text { anteriormente }\end{array}$ & $\begin{array}{l}\text { Como obteve informações } \\
\text { sobre o atual serviço }\end{array}$ & $\begin{array}{l}\text { Tempo de utilização } \\
\text { do (s) serviço (s) }\end{array}$ & Local de residência \\
\hline 03 & Amiga & Utiliza dois serviços de saúde & Camaçari \\
\hline 03 & M édico & Utiliza dois serviços de saúde & Simões Filho \\
\hline 00 & Filho faz tratamento no serviço & Utiliza apenas este serviço de saúde & IAPI \\
\hline Não especificou noㅡ & Diretora da escola & Utiliza apenas este serviço de saúde & Cidade baixa \\
\hline Não especificou noㅡ & M édica do Plano de Saúde & Utiliza dois serviços de saúde & Cidade baixa \\
\hline 03 & Vizinha & Utiliza apenas este serviço & $|A P|$ \\
\hline 02 & M édica do posto & Utiliza apenas este serviço & Valéria \\
\hline 02 & M édico otorrino & Utiliza apenas este serviço & Cajazeiras \\
\hline Não especificou nํㅡ & Encaminhada por outro serviço de saúde & Utiliza apenas este serviço & IAPI \\
\hline 02 & Cunhado com o mesmo problema & Utiliza apenas este serviço & Cabula \\
\hline Não especificou nํㅜ & M édico & $\begin{array}{l}\text { Utiliza este serviço para o } \\
\text { atendimento fonoaudiológico e } \\
\text { convênio }\end{array}$ & Canabrava \\
\hline 02 & Otorrino do serviço & Utiliza apenas este serviço & Pirajá \\
\hline 02 & Colegas & Utiliza dois serviços de saúde & Cajazeiras \\
\hline Não especificou $\mathrm{n}^{0}$ & Encaminhada por um serviço de saúde & Utiliza apenas este serviço & Cosme de Farias \\
\hline Não especificou $\mathrm{n}^{0}$ & M édica & Utiliza dois serviços de saúde & Periperi \\
\hline 03 & M édica & Utiliza dois serviços de saúde & São Cristóvão \\
\hline 02 & Serviço de Saúde em São Paulo & Utiliza dois serviços de saúde & Pernambués \\
\hline 01 & Irmão é usuário da instituição & Utiliza apenas este serviço & São Caetano \\
\hline 02 & M édica & Utiliza quatro serviços de saúde & Pirajá \\
\hline 01 & Irmã & Utiliza apenas este serviço & Município de Irara \\
\hline Não especificou noㅡ & Filha (profissional de saúde) & Utiliza dois serviços de saúde & Cabula \\
\hline 01 & Colegas & Utiliza apenas este serviço & São Caetano \\
\hline 01 & Filho é usuário do serviço & Utiliza apenas este serviço & Vasco da Gama \\
\hline 01 & Assistente social & Utiliza dois serviços de saúde & Stell'a Maris \\
\hline 01 & Televisão & $\begin{array}{l}\text { Utiliza apenas este serviço saúde e } \\
\text { escola especial }\end{array}$ & Arembepe \\
\hline 01 & Assistente Social & Utiliza apenas este serviço & $\begin{array}{l}\text { São Francisco do } \\
\text { Conde }\end{array}$ \\
\hline 01 & Amiga da família quetrabalha no serviço & Utiliza apenas este serviço & Sussuarana \\
\hline 01 & $\begin{array}{l}\text { M ulher no ponto de ônibus informou } \\
\text { sua esposa }\end{array}$ & Utiliza apenas este serviço & Vila Nova Brasília \\
\hline 03 & Por uma profissional de saúde & Utiliza quatro serviços de saúde & Suburbana \\
\hline 01 & Por uma profissional de saúde & Utiliza dois serviços de saúde & Cidade baixa \\
\hline
\end{tabular}

